\title{
Effect of Chlorides on Conductivity and Dielectric Constant in Hardened Cement Mortar: NDT for Durability Evaluation
}

\author{
Sunkook Kim,, ${ }^{1}$ Joowon Kang, ${ }^{2}$ Sang-Hyo Lee, ${ }^{3}$ and Yong Han Ahn ${ }^{3}$ \\ ${ }^{1}$ Multi-Functional Nano/Bio Electronics Lab, Department of Electronics and Radio Engineering, Kyung Hee University, \\ Gyeonggi 446-701, Republic of Korea \\ ${ }^{2}$ School of Architecture, Yeungnam University, 280 Daehak-ro, Gyeongbuk 712-749, Republic of Korea \\ ${ }^{3}$ Division of Architecture and Architectural Engineering, Hanyang University-ERICA, Gyeonggi 15588, Republic of Korea
}

Correspondence should be addressed to Yong Han Ahn; yonghan77@gmail.com

Received 22 February 2016; Accepted 27 April 2016

Academic Editor: Yuyin Wang

Copyright (C) 2016 Sunkook Kim et al. This is an open access article distributed under the Creative Commons Attribution License, which permits unrestricted use, distribution, and reproduction in any medium, provided the original work is properly cited.

Dielectric constant and conductivity, the so-called EM properties (electromagnetic), are widely adopted for NDT (Nondestructive Technique) in order to detect damage or evaluate performance of concrete without damage to existing RC (reinforced concrete). Among deteriorating agents, chloride ion is considered as one of the most critical threats due to rapid penetration and direct effect on steel corrosion. In the work, cement mortar samples with $3 \mathrm{w} / \mathrm{c}$ (water-to-cement) ratios and 4 levels of chloride addition are considered. Conductivity and dielectric constant are measured in the normal frequency range. They increase with strength of mortar and more chloride ions due to denser pore formation. Furthermore, the behaviors of measured EM property are investigated with carbonation velocity and strength, which shows an attempt of application to durability evaluation through EM measurement.

\section{Introduction}

Nondestructive Techniques (NDT) are widely used for evaluation of physical and durability performance in concrete structures. Among various techniques, the techniques using electromagnetic (EM) properties are increasingly applied as an alternative for performance evaluation in RC (reinforced concrete) structure [1,2]. Several researchers have focused on EM properties in cement-based materials. These researches can be classified into several categories. Many studies related to the characterization of EM properties in cement-based materials have been performed [3-5]. They cover not only Ordinary Portland Cement (OPC) but also cement-based matrix with mineral admixtures such as fly ash [6-9]. Some of the studies focused on the variations of EM properties in wide frequency range [3]. Recently, EM properties are applied for durability evaluation in concrete such as permeability and the diffusion coefficient [10-12]. Usually, the models which are made up of porosity, solid paste, and saturation of water can provide dielectric constant and loss factor through complex equations $[2,13-15]$. The models have been applied to the deteriorated RC structures considering permittivity in saline water. The evaluation techniques like monitoring and condition assessment are also proposed through the unique characteristics of EM measurement [15-18]. Recently, NDT techniques using EM properties are applied to the evaluation of delamination in composite member repaired with glass fiber reinforced plastic (GFRP) [19-21].

The porosity and saturation in concrete have a great effect not only on the EM properties but also on the durability characteristics in concrete. During hydration process, pores are naturally generated in the concrete and the amount of pores (porosity) has a close relationship with the structural and durability performance [22-24]. As porosity plays an important role in intrusion of deteriorating agent, it is mainly considered to explain the mechanism of diffusion and permeation of ion [25-28].

This work is focused on the characterization of EM properties in cement mortar with chloride ion. The measured EM properties are compared with typical concrete performance like carbonation velocity and strength. In the practical point of view, the characteristics of EM properties observed in 
TABLE 1: Influencing parameters for EM properties.

\begin{tabular}{|c|c|c|}
\hline Type & Parameters & Characteristics of EM properties \\
\hline \multirow{3}{*}{ Interior condition } & Water amount & $\begin{array}{l}\text { (i) Strongly affect dielectric constant and conductivity } \\
\text { (ii) Increase with larger amount of water }\end{array}$ \\
\hline & Porosity & (i) Decrease with larger porosity \\
\hline & Chloride ion & (i) Greatly increase with larger amount of chloride in water \\
\hline \multirow{2}{*}{ Exterior condition } & Temperature & (i) Increase with higher temperature $(<10-12 \mathrm{GHz})$ \\
\hline & Humidity & (i) Increase with higher humidity \\
\hline \multirow[t]{2}{*}{ Measurement condition } & Frequency & $\begin{array}{l}\text { (i) Dielectric constant: decrease with higher frequency } \\
\text { (ii) Conductivity: increase with higher frequency }\end{array}$ \\
\hline & Measuring surface & (i) Increase with larger contact surface \\
\hline
\end{tabular}

TABLE 2: Detailed mix proportions.

\begin{tabular}{lccccc}
\hline w/c $(\%)$ & Slump $(\mathrm{cm})$ & Water $\left(\mathrm{kg} / \mathrm{m}^{3}\right)$ & Cement $\left(\mathrm{kg} / \mathrm{m}^{3}\right)$ & Sand $\left(\mathrm{kg} / \mathrm{m}^{3}\right)$ & 1,164 \\
Air content $(\%)$ \\
\hline 45 & 15 & 277 & 615 & 1,353 & 0.92 \\
55 & 15 & 267 & 485 & 1,445 & 1.00 \\
65 & 15 & 267 & 407 & 1.54 \\
\hline
\end{tabular}

the work can be utilized for not only strength evaluation but also durability evaluation.

\section{Conductivity and Dielectric Constant}

2.1. Conductivity and Dielectric Constant in Porous Media $[3,20]$. All materials have a unique set of EM properties. Nonmetallic materials like concrete can be characterized by two independent electromagnetic properties: (1) the complex permittivity $\left(\varepsilon^{*}\right)$ and (2) the complex permeability $\left(\mu^{*}\right)[3]$. Since most of the dielectric materials such as concrete are nonmagnetic, the permeability $\mu^{*}$ of the dielectric materials is very close to that of free space $\left(\mu_{0}=4 \pi \times 10^{-7}\right.$ henries/meter). Thus, it is enough to focus on the complex permittivity $\varepsilon^{*}$ defined by $[3,20]$

$$
\varepsilon^{*}=\varepsilon^{\prime}-j \varepsilon^{\prime \prime},
$$

where $\varepsilon^{\prime}$ and $\varepsilon^{\prime \prime}$ are the real and imaginary parts of the complex permittivity and $j=\sqrt{-1}$. Equation (1) can be rewritten as (2) when considering the permittivity in free space $\varepsilon_{0}\left(8.854 \times 10^{-12} \mathrm{farad} / \mathrm{m}\right)$. Equation (2) can be rewritten as (3) which is dimensionless [3, 20]:

$$
\begin{aligned}
& \frac{\varepsilon^{*}}{\varepsilon_{0}}=\frac{\varepsilon^{\prime}}{\varepsilon_{0}}-j \frac{\varepsilon^{\prime \prime}}{\varepsilon_{0}}, \\
& \varepsilon_{r}^{*}=\varepsilon_{r}^{\prime}-j \varepsilon_{r}^{\prime \prime},
\end{aligned}
$$

where $\varepsilon_{r}^{*}$ is the relative complex permittivity. $\varepsilon_{r}^{\prime}$ and $\varepsilon_{r}^{\prime \prime}$ are the real and imaginary parts of the relative complex permittivity, respectively.

The real part of the relative complex permittivity, $\varepsilon_{r}^{\prime}$, also known as the dielectric constant, is a depiction of how much energy can be stored in a material from an external electric field. The imaginary part of the relative complex permittivity, $\varepsilon_{r}^{\prime \prime}$, represents how dissipative a material is to an external electric field. This value can be simply referred to the loss factor $[3,22]$. The equivalent conductivity $\sigma(\mathrm{mhos} / \mathrm{m})$ can be written in terms of the imaginary part of the complex permittivity, $\varepsilon^{\prime \prime}$, as shown in

$$
\sigma=\varepsilon^{\prime \prime} \omega=\left(\varepsilon_{r}^{\prime} \varepsilon_{0} \tan \delta\right)(2 \pi f),
$$

where $\omega$ is angular frequency of EM wave $(\mathrm{rad} / \mathrm{sec}), \tan \delta$ is loss tangent (the ratio of energy lost to energy stored in a material), and $f$ is the number of cycles per second $(\mathrm{Hz})$. These EM properties are not constant and are dependent upon the frequency, temperature, moisture content, chloride content, and concrete mix constituents [2-4].

The influencing parameters can be summarized as Table 1 in the view of porous media. Exterior conditions like temperature and humidity and the measurement condition such as the range of frequency also have effects on the EM properties.

\section{Conductivity and Dielectric Constant in Concrete}

\subsection{Experimental Program}

3.1.1. Measurement of Dielectric Constant and Conductivity. The OPC mortars with 3 different w/c ratios $(0.45,0.55$, and 0.65) are prepared. For each case of w/c ratios, 4 different chloride contents $\left(0.0,0.6,1.2\right.$, and $\left.3.6 \mathrm{~kg} / \mathrm{m}^{3}\right)$ are added at the mix stage. The chloride ion within $1.2 \sim 3.6 \mathrm{~kg} / \mathrm{m}^{3}$ is meaningful since chloride content of $1.2 \mathrm{~kg} / \mathrm{m}^{3}$ is regarded as a critical threshold which can cause steel corrosion in concrete. Thus, a total of $12 \mathrm{mix}$ conditions are prepared for the comparative investigation. Each sample was kept in air-curing condition for 4 weeks after mixing. The mix proportions for OPC mortar are listed in Table 2.

For the test, cement mortar is used for EM properties in order to prevent a measurement error due to direct contact on the coarse aggregate. Cylindrical samples 


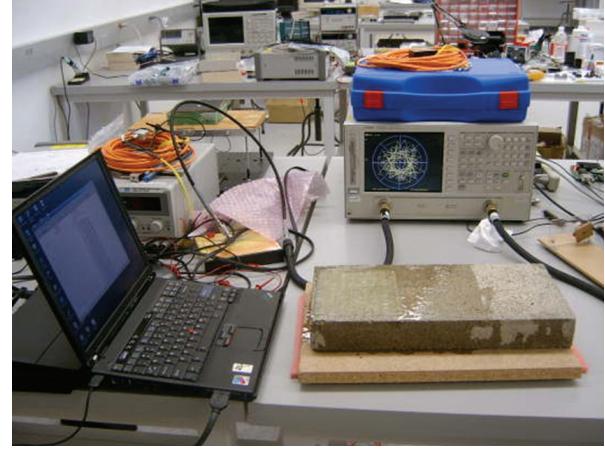

FIGURE 1: Setup for EM measurement.

$(100 \mathrm{~mm} \times 200 \mathrm{~mm})$ are made for the compressive strength test and the disk type specimens $(100 \mathrm{~mm}$ diameter $\times 20 \mathrm{~mm}$ thickness) are prepared for EM property measurement. A concrete depth of over $5 \mathrm{~mm}$ was reported to have insignificant effect from reflected microwaves [18].

The measurement setup is shown in Figure 1. The package for EM measurement has a dielectric probe kit which includes analyzing software, an open ended coaxial probe (OECP), a network analyzer, and a laptop computer. Conductivity and dielectric constant are measured by placing the probe in contact with a flat face of a solid surface. The network analyzer sends and receives microwaves through the probe over a frequency range of $0.2 \mathrm{GHz}$ to $20 \mathrm{GHz}$ with an interval of $0.4 \mathrm{GHz}$.

For the calibration of the test system using the OECP, predefined property values for the reflected signal should be prepared over the measuring frequency range [29]. In the test, the calibration is performed in the air, namely, free space, and in the water with $25^{\circ} \mathrm{C}$ prior to the measurement.

3.1.2. Compressive Strength. Compressive strength tests are performed referring to Korea Standard [30]. Trifold cement mortar samples with $100 \mathrm{~mm}$ of diameter and $200 \mathrm{~mm}$ of height are prepared. The samples have been kept for 4 weeks in the same curing condition and compressive strength test was performed after 1-day exposure to room condition.

3.1.3. Carbonation Test. After 4 weeks of curing, the samples were kept in the condition of relative humidity at $60 \%$ and $25^{\circ} \mathrm{C}$ temperature for 2 weeks. And then the accelerated carbonation test is performed for 8 weeks referring to the Korea Standard [31, 32]. For 1-dimensional accelerated carbonation test, the sides of specimens are coated with epoxy except for top surface. The conditions for accelerated carbonation test are listed in Table 3. The photos for compressive strength test and carbonation test are shown in Figure 2. The carbonation test is performed on cement mortar samples $(50 \mathrm{~mm}$ of thickness) without chloride contents.

\subsection{Test Results}

3.2.1. Measurement of Dielectric Constant and Conductivity. In the test, the measurements from OECP are repeatedly
TABLE 3: Conditions for accelerated carbonation test.

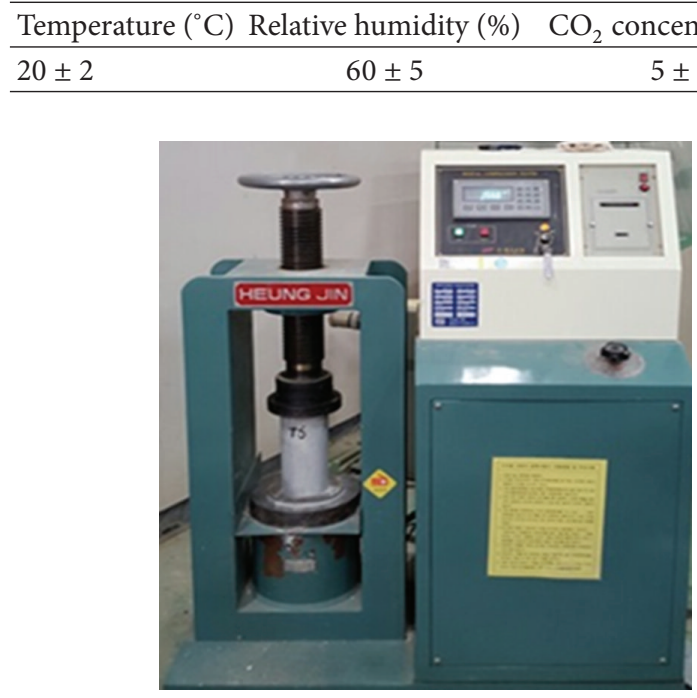

(a) Compressive strength

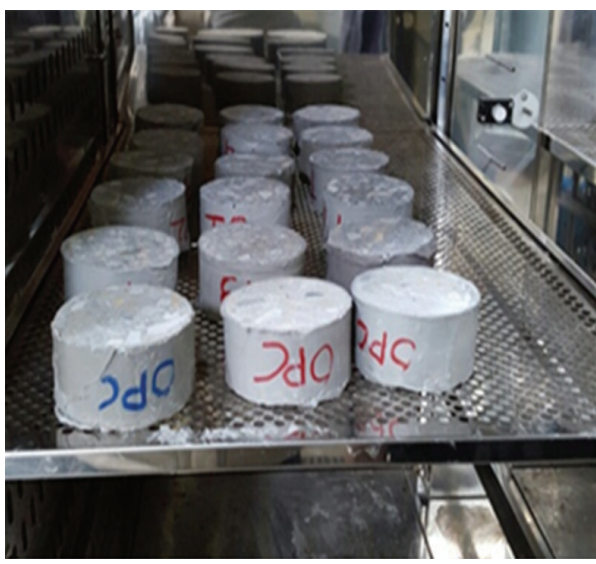

(b) Samples in the carbonation chamber

FIGURE 2: Photos for compressive strength and carbonation test.

performed 10 times for each disk samples, and the values of dielectric constant and conductivity are averaged. The range of frequency is $0.2 \sim 20 \mathrm{GHz}$ and several points of $0.2,5,10,15$, and $20 \mathrm{GHz}$ are selected and measured in a room condition with $60 \%$ relative humidity and $20 \sim 22^{\circ} \mathrm{C}$ temperature. The measured results with different $\mathrm{w} / \mathrm{c}$ ratios are plotted in Figures 3 5.

As shown in Figures 3 5, conductivity becomes larger and dielectric constant decreases with the increase of frequency. The changing behavior with frequency is consistent with the previous researches $[18,21]$. With the smaller pores, mortar surface has more contact area with probe and this causes higher conductive and dielectric constant. The larger addition of $\mathrm{NaCl}$ causes more dense porosity [33, 34].

3.2.2. Compressive Strength Results. The compressive strength shows a close relationship with w/c ratios in cement mortar but it shows insignificant variations with chloride amount included in the test. The drop of $\mathrm{pH}$ due 


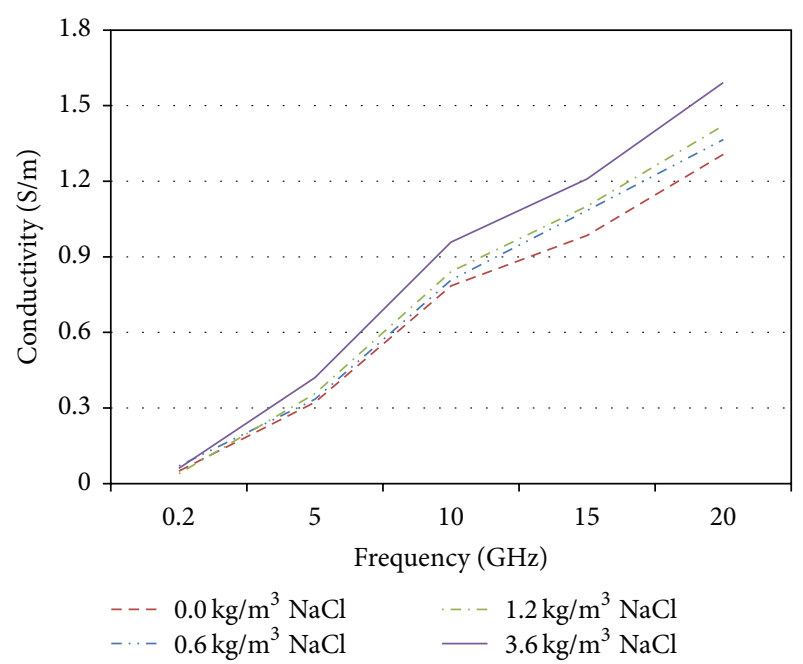

(a) Conductivity

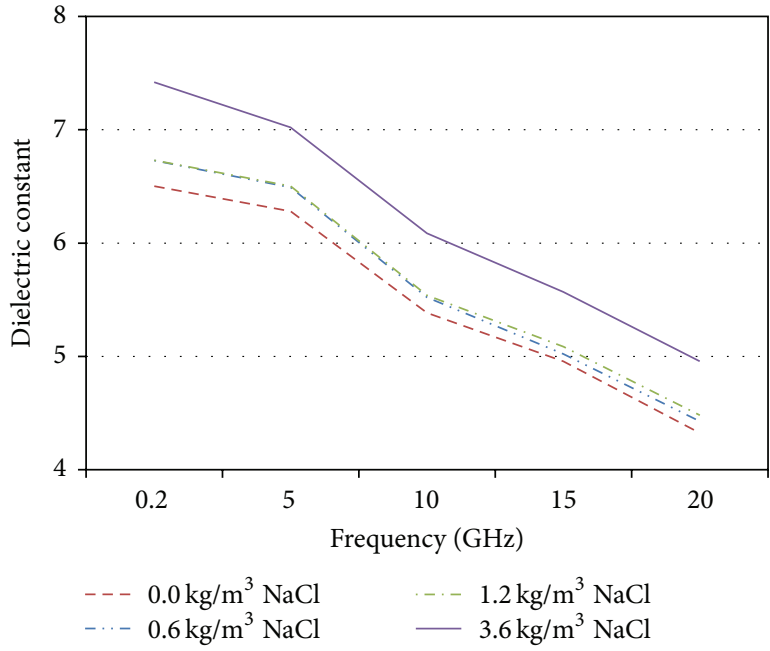

(b) Dielectric constant

FIGURE 3: Conductivity and dielectric constant (w/c 0.45).

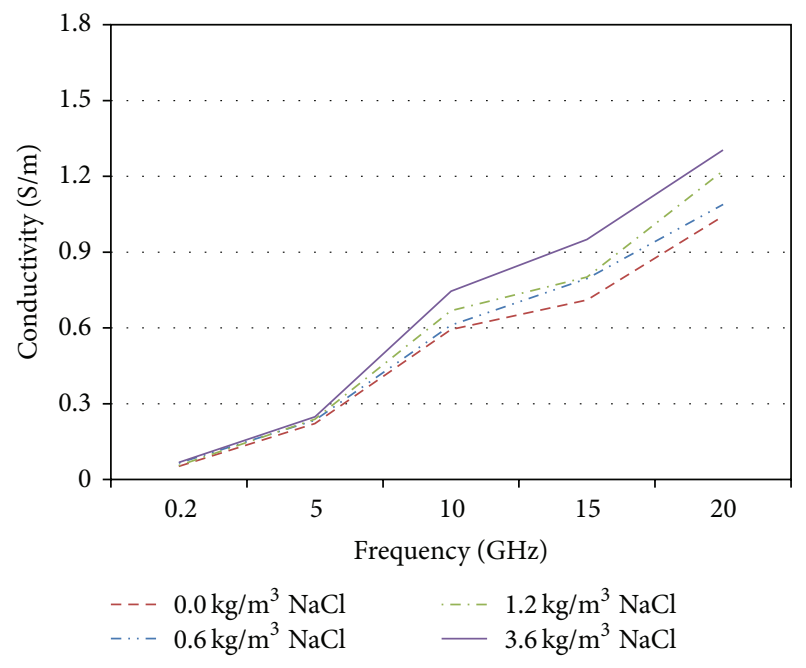

(a) Conductivity

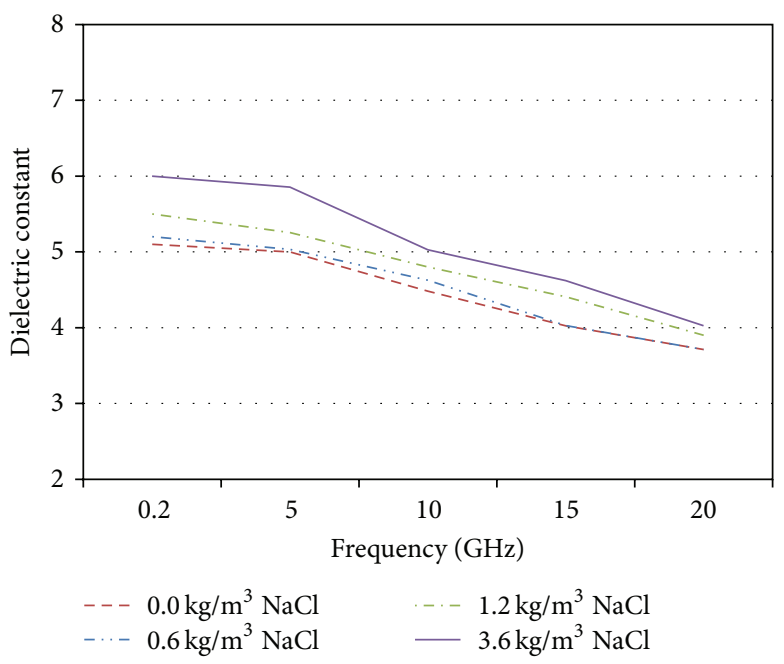

(b) Dielectric constant

FIgure 4: Conductivity and dielectric constant (w/c 0.55).

to the addition of calcium chloride $\left(\mathrm{CaCl}_{2}\right)$ can accelerate the hydration activity so that the compressive strength in early-aged stage rapidly increases [33]. Concrete with sodium chloride $(\mathrm{NaCl})$ is reported to show little change in hydration activity but significant effects on drying shrinkage due to the altered pore distribution [34]. The test results of compressive strength are shown in Figure 6 where one can indicate that the compressive strength has no clear relationship with the chloride contents. The similar results related to the compressive strength can be found in previous research [24]. Traditional strength reduction is found in Figure 6 with increasing w/c ratio.

3.2.3. Accelerated Carbonation Test Result. It is also found that concrete with low w/c ratio shows small carbonation depth since it has low diffusion coefficient of $\mathrm{CO}_{2}$ and large amount of hydrates such as $\mathrm{CHS}$ and $\mathrm{Ca}(\mathrm{OH})_{2}$ which have potential to keep high $\mathrm{pH}$ in pore water $[26,35]$. Carbonation velocity is usually adopted for carbonation resistance based on the assumption that carbonation depth has linear relationship with square root of exposed time [36, 37]. In Figure 7, the results of accelerated carbonation test are plotted, which shows slower carbonation progress with lower $\mathrm{w} / \mathrm{c}$ ratio. Carbonation velocity through regression analysis can be summarized in Table 4 .

\section{Characteristics of EM Properties for Durability Evaluation}

4.1. EM Characteristics and $w / c$ Ratios. For the purpose of comparison of the results, EM properties corresponding to 


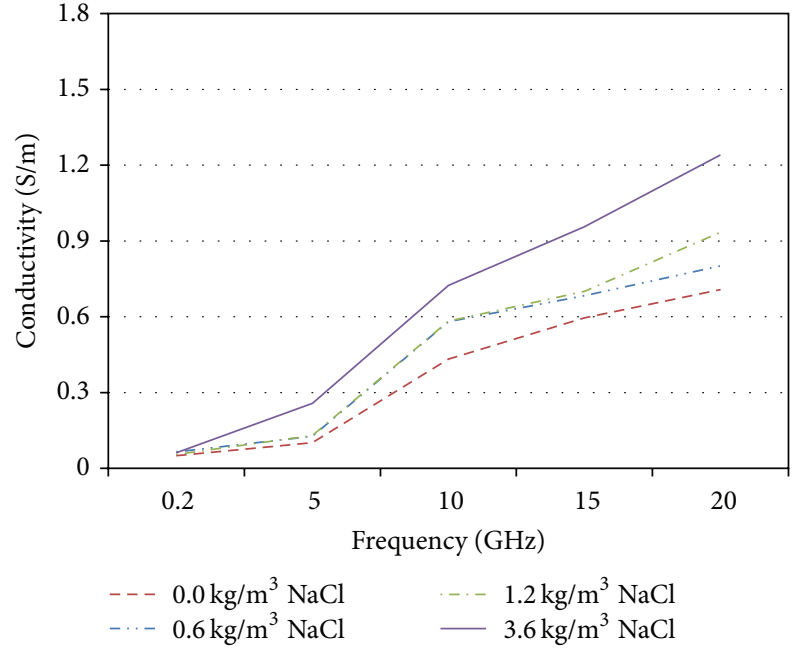

(a) Conductivity

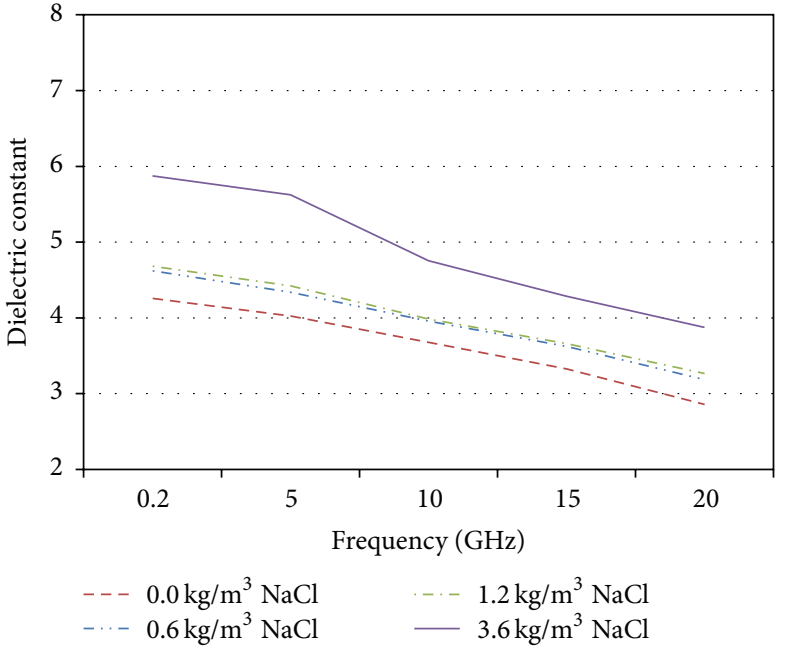

(b) Dielectric constant

FIGURE 5: Conductivity and dielectric constant (w/c 0.65).

TABLE 4: Carbonation velocity.

\begin{tabular}{cccc}
\hline w/c & $\begin{array}{c}\text { Carbonation velocity } \\
\left(\mathrm{mm} / \text { week }^{0.5}\right)\end{array}$ & $\begin{array}{c}\text { Carbonation depth } \\
D(\mathrm{~mm})\end{array}$ & $R^{2}$ \\
\hline 0.45 & 0.5788 & $D=0.579 \times \sqrt{\text { week }}$ & 0.9795 \\
0.55 & 0.8445 & $D=0.845 \times \sqrt{\text { week }}$ & 0.9916 \\
0.65 & 1.1167 & $D=1.117 \times \sqrt{\text { week }}$ & 0.9641 \\
\hline
\end{tabular}

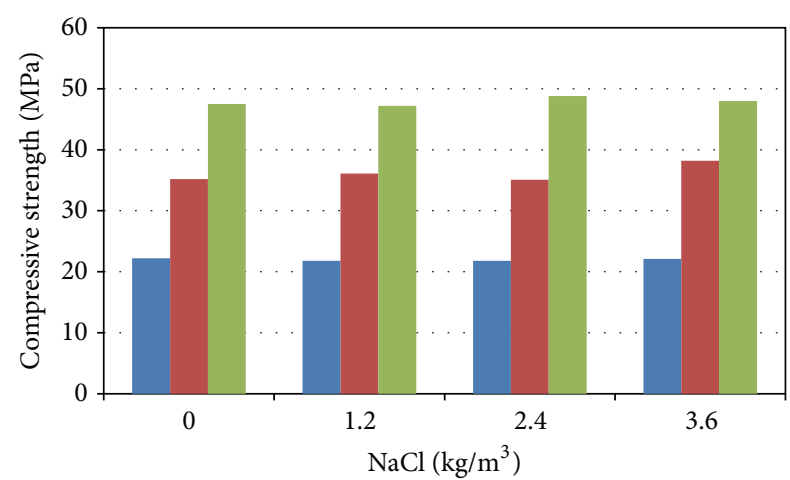

- w/c: 0.65

- w/c: 0.55

- $\mathrm{w} / \mathrm{c}: 0.45$

FIGURE 6: Compressive strength with different chloride contents.

$5 \sim 20 \mathrm{GHz}$ range are, respectively, averaged as one value to obtain parameter. Each averaged value of conductivity and dielectric constant is plotted in Figure 8 with w/c ratios considering chloride contents.

Typically, porosity in cement mortar has effect on the conductivity and dielectric constant. In cement mortar, porosity becomes smaller with decrease in w/c ratios due to abundant hydrates, and the reduced porosity causes higher EM properties [22, 23, 38]. Usually, permittivity of cement gel

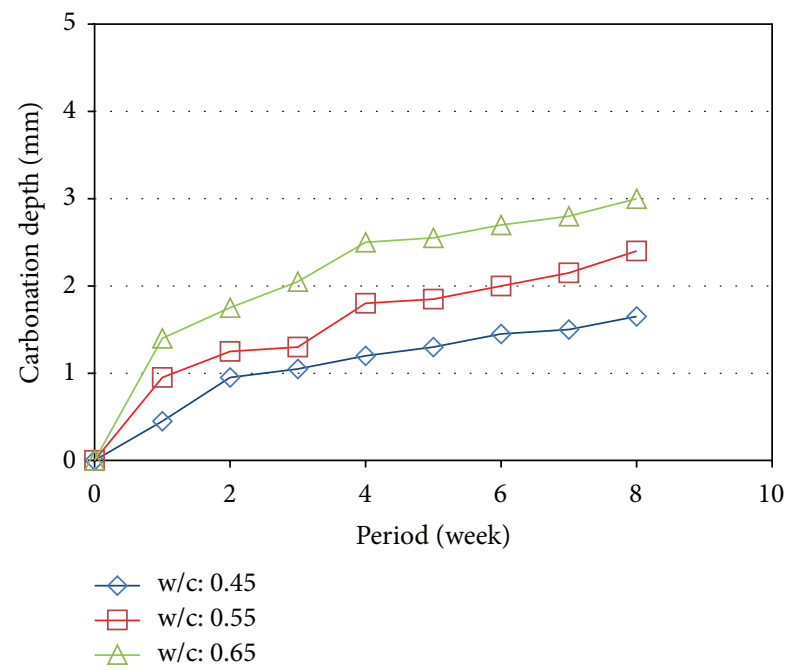

FIGURE 7: Carbonation depth with exposed period.

is in the level of $5 \sim 10$ and this is larger than that of air $(=1.0)$ $[2,13]$. One can also indicate that, for the samples containing the same w/c ratios, more chloride content leads to higher EM properties due to reduced porosity.

4.2. EM Characteristics and Compressive Strength. As in Section 3.2.2, the addition of $\mathrm{NaCl}$ cannot cause a big change in strength. The averaged EM properties can compare the results of compressive strength as in Figure 9. EM properties (dielectric constant and conductivity) without chloride content are used for the comparison with the results since they are varying significantly with chloride addition. Compressive strength is reported to have linear relationship with $\mathrm{w} / \mathrm{c}$ ratio [22]. As shown in Figure 8, EM properties without chloride content have linear relationship with w/c ratio with high determination coefficient $\left(R^{2}\right)$, so that linear relationship 


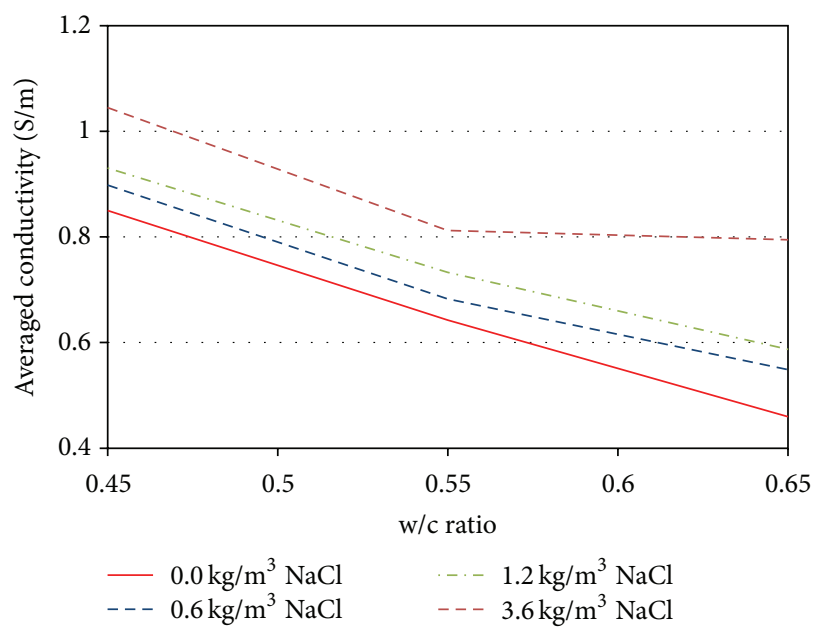

(a) Averaged conductivity

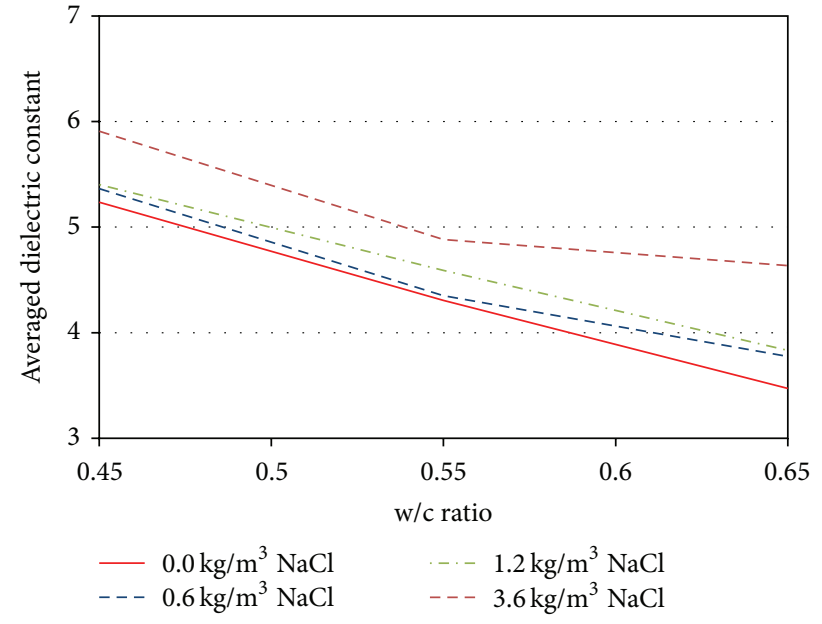

(b) Averaged dielectric constant

Figure 8: Averaged EM properties with different w/c ratios and chloride contents.

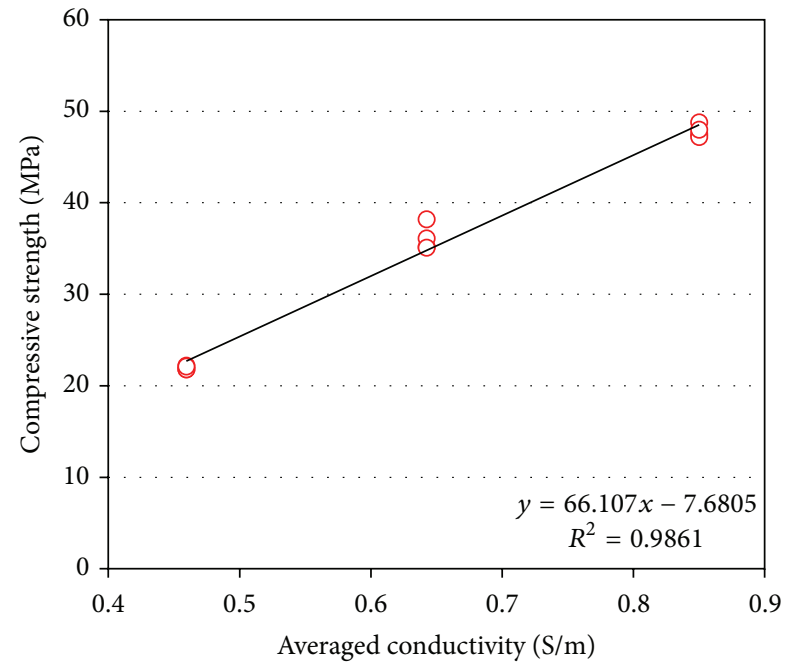

(a) Conductivity and strength

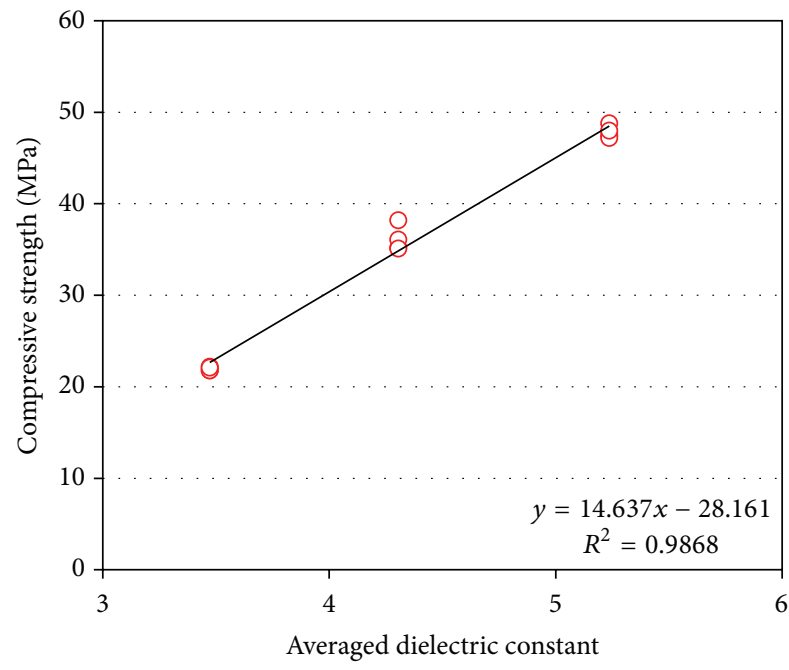

(b) Dielectric constant and strength

FIGURE 9: EM properties and compressive strength.

is found between EM properties and strength as shown in Figure 9.

4.3. EM Characteristics and Carbonation Velocity. For porous media, the diffusion mechanism in concrete is also closely related with porosity characteristics [26-28]. In Figure 10, the averaged EM properties are compared with the carbonation velocity obtained from the accelerated carbonation test. The results are only for the case without chloride contents.

The carbonation velocity is observed in linear proportion to the $\mathrm{w} / \mathrm{c}$ ratios and the trend can be found in conventional equations for the prediction of carbonation depth $[26,36]$. For the cement mortar without chloride amount, it is found that that the averaged EM properties decrease with the high carbonation velocity, which is consistent with the results in high w/c and low compressive strength. Considering the results in strength and carbonation depth, the lower w/c ratio in cement mortar causes larger content of hydrates, which yields high strength and low porosity. The dense structure shows relatively high EM properties. With increasing strength due to larger hydrates and lower porosity, the resistance to carbonation also increases due to low $\mathrm{CO}_{2}$ diffusion and more carbonatable materials- $\mathrm{Ca}(\mathrm{OH})_{2}$. In Figure 10, higher carbonation velocity, which means coarse structure, shows lower conductivity and electric constant.

\subsection{EM Characteristics and Chloride Content in Cement Mor-} tar. In the water-submerged condition, chloride ion does not significantly affect dielectric constant; however, loss factor which causes attenuation is greatly changed due to increase in ohmic conductivity [3]. In cement mortar, both conductivity and dielectric constant increase with larger amount 


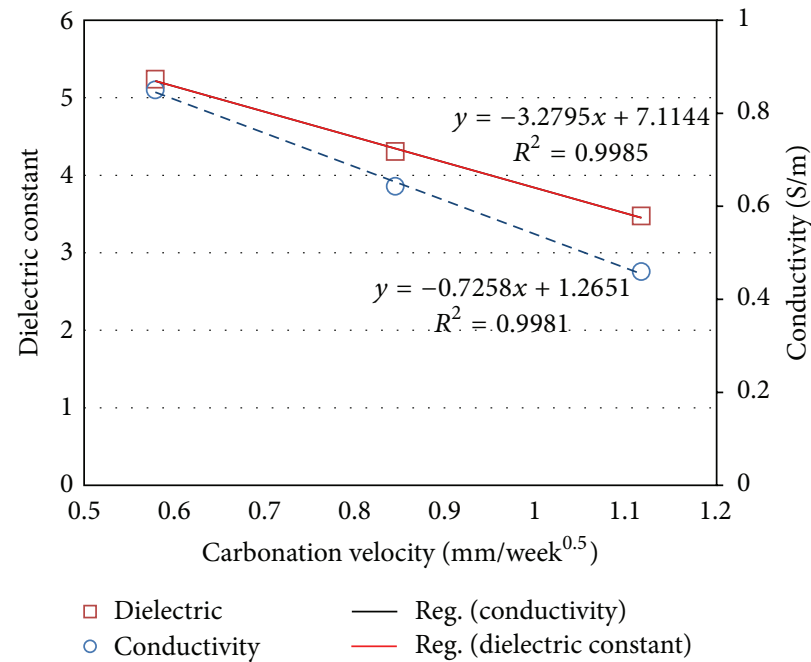

FIGURE 10: Relationship between carbonation velocity and EM properties.

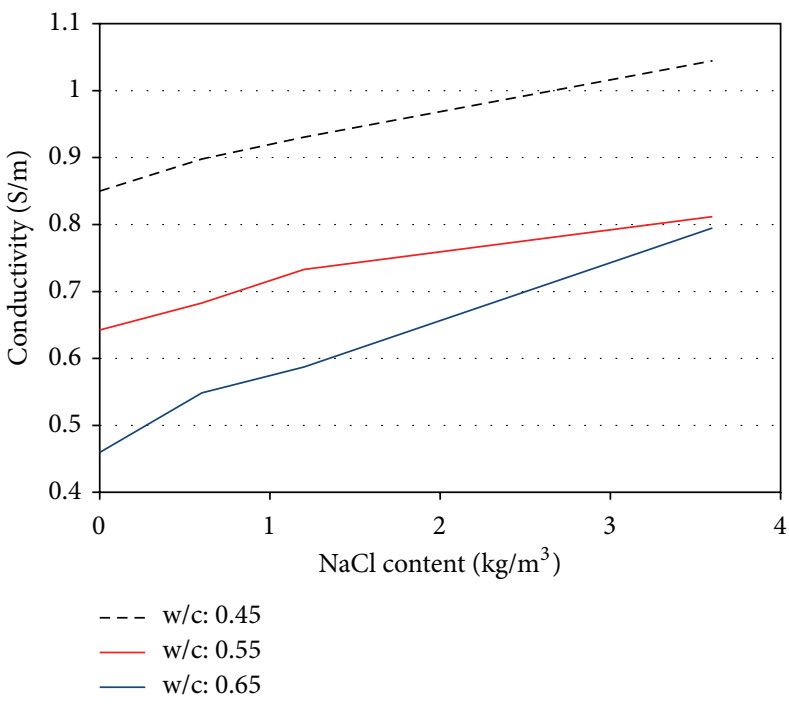

(a) Conductivity variation

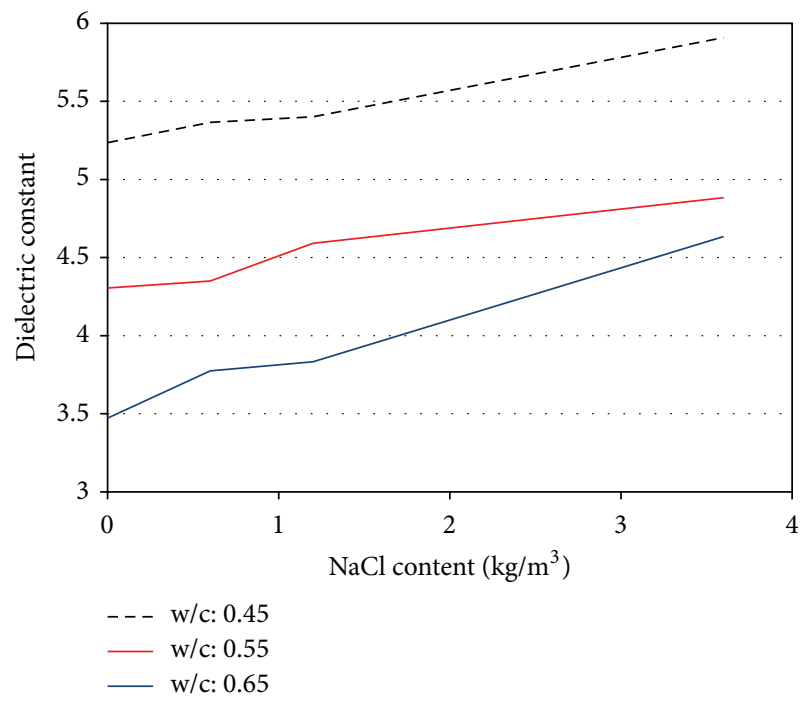

(b) Dielectric constant

FIGURE 11: Effect of chloride contents on conductivity and dielectric constant.

of chloride amount. It is because the chloride ion in initial mix causes smaller pore distribution in OPC mortar, and sodium ion dissolved in pore water can increase conductivity and dielectric constant. In Figure 11, the effect of chloride on EM properties is plotted with varying chloride contents. The result in higher $\mathrm{w} / \mathrm{c}$ ratio shows more rapid increase in both conductivity and dielectric constant because the coarse pore structure in OPC mortar with higher w/c ratio is more affected by chloride ion which can cause the densification of pore structure.

The regression analysis is performed with increasing ratios to noncontaminated OPC mortar and is plotted in Figure 12. The linear relationships between EM properties and chloride content are summarized in Table 5. In Table 5, the gradient of slope means the effect of chloride ion on
EM properties. Lower w/c ratio shows higher strength in concrete and lower dependency of chloride ion; however, mix conditions with high $\mathrm{w} / \mathrm{c}$ ratio $(0.65)$ show clear increase in chloride effect. When chloride ion is added to $3.6 \mathrm{~kg} / \mathrm{m}^{3}$, conductivity and dielectric constant increase to $173 \%$ and $134 \%$, respectively. The relationship shows clear linearity with high determination coefficient over 0.9 , which strongly shows applicability as NDT for evaluation of chloride contamination for cement mortar.

\section{Concluding Remark}

Among various nondestructive testing (NDT) techniques, electromagnetic properties of conductivity and dielectric constant are attempted for an evaluation of chloride effect 


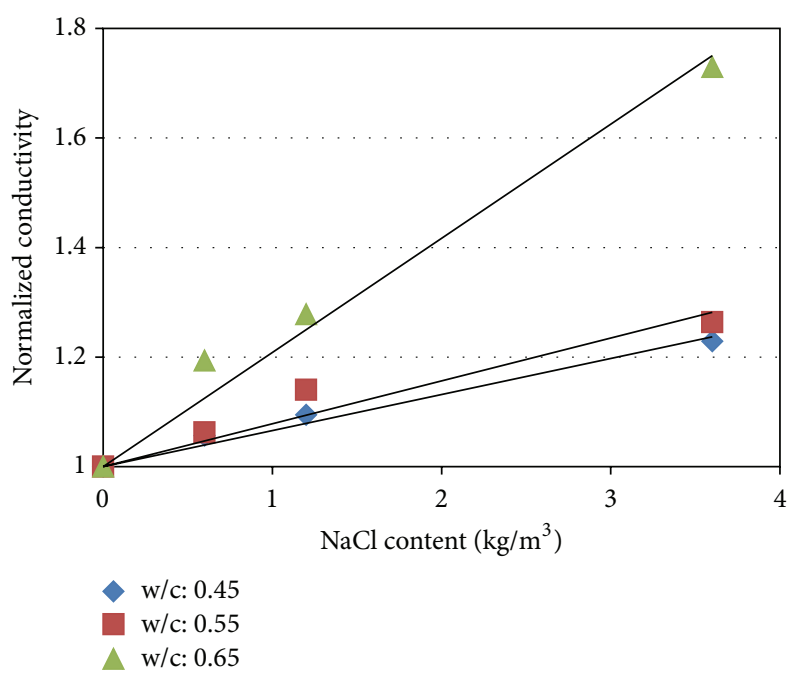

(a) Normalized conductivity

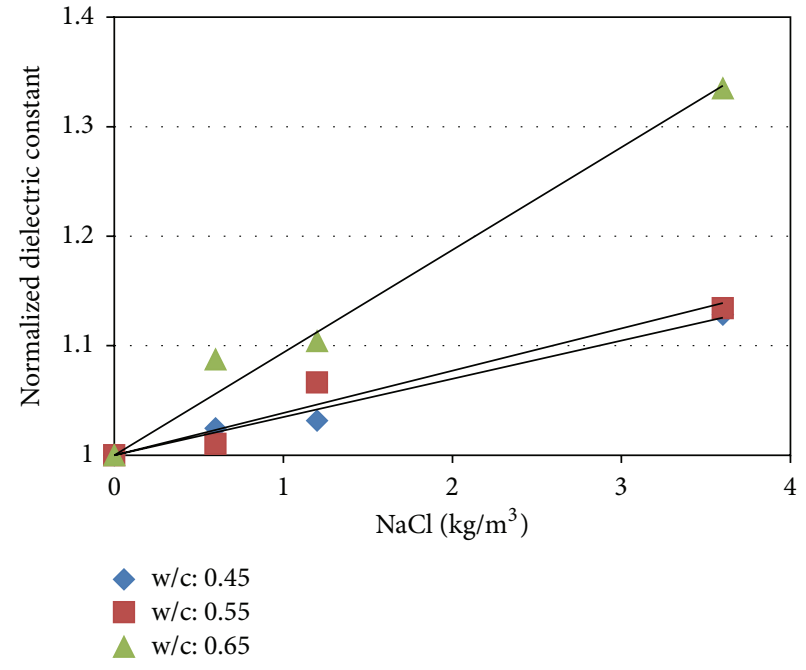

(b) Normalized dielectric constant

FIGURE 12: Increasing ratios of EM properties with chloride contents.

TABLE 5: Summary of the regression analysis.

\begin{tabular}{lrcc}
\hline \multicolumn{2}{c}{ w/c ratios (\%) } & \multirow{2}{c}{$A$} & $R^{2}$ \\
\multicolumn{2}{c}{ Increasing ratios $Y=A X+1$} & & 0.9793 \\
Conductivity & 0.45 & 0.2084 & 0.9294 \\
& 0.55 & 0.0783 & 0.9791 \\
\hline \multirow{3}{*}{ Dielectric constant } & 0.65 & 0.0659 & 0.9830 \\
& 0.45 & 0.0937 & 0.9484 \\
& 0.55 & 0.0386 & 0.9866 \\
\hline
\end{tabular}

in cement-based construction material. The conclusions on effect of chlorides on conductivity and dielectric constant in hardened cement mortar are as follows.

(1) Through the measurement of electromagnetic properties within the $0.2 \sim 20 \mathrm{GHz}$ frequency range, the patterns of dielectric constant and conductivity are investigated in cement mortar with $0.0 \sim 3.6 \mathrm{~kg} / \mathrm{m}^{3}$ of chloride addition. The relationships between electromagnetic properties and engineering parameters like w/c ratios, carbonation velocity, and the induced chloride content are compared as well.

(2) The carbonation velocities and compressive strength are measured for OPC mortar with different w/c ratios. Then, the results are compared with averaged EM properties. Both conductivity and dielectric constant linearly decrease with increasing carbonation velocity and decreasing compressive strength with high determination coefficient. With more addition of chloride content to cement mortar, dielectric constant and conductivity are observed to linearly increase. Referred to the results without chlorides, the cement mortar containing $3.6 \mathrm{~kg} / \mathrm{m}^{3}$ of chloride amount shows $173 \%$ increasing of dielectric constant and 134\% increasing of conductivity. The linear regression with high determination coefficient is also observed with more chloride content.

\section{Competing Interests}

The authors declare that there is no conflict of interests regarding the publication of this paper.

\section{Acknowledgments}

This research was supported by Basic Science Research Program through the National Research Foundation of Korea (NRF) funded by the Ministry of Science, ICT \& Future Planning (no. 2015R1A5A1037548).

\section{References}

[1] J. Glanvile and A. Nevile, "Prediction of concrete durability," in Proceedings of the STATS 21st Anniversary Conference, E\&FN SPON, London, UK, November 1995.

[2] U. B. Halabe, A. Sotoodehnia, K. R. Maser, and E. A. Kausel, "Modeling the electromagnetic properties of concrete," ACI Materials Journal, vol. 90, no. 6, pp. 552-563, 1993.

[3] H. C. Rhim and O. Büyüköztürk, "Electromagnetic properties of concrete at microwave frequency range," ACI Materials Journal, vol. 95, no. 3, pp. 262-271, 1998.

[4] M. N. Soutsos, J. H. Bungey, S. G. Millard, M. R. Shaw, and A. Patterson, "Dielectric properties of concrete and their influence on radar testing," NDT \& E International, vol. 34, no. 6, pp. 419425, 2001.

[5] F. H. Wittmann and F. Schlude, "Microwave absorption of hardened cement paste," Cement and Concrete Research, vol. 5, no. 1, pp. 63-71, 1975.

[6] W. J. McCarter, T. M. Chrisp, G. Starrs, and J. Blewett, "Characterization and monitoring of cement-based systems 
using intrinsic electrical property measurements," Cement and Concrete Research, vol. 33, no. 2, pp. 197-206, 2003.

[7] W. J. McCarter, T. M. Chrisp, and G. Starrs, "The early hydration of alkali-activated slag: developments in monitoring techniques," Cement and Concrete Composites, vol. 21, no. 4, pp. 277-283, 1999.

[8] W. J. McCarter, G. Starrs, and T. M. Chrisp, "Immittance spectra for Portland cement/fly ash-based binders during early hydration," Cement and Concrete Research, vol. 29, no. 3, pp. 377-387, 1999.

[9] W. J. McCarter, G. Starrs, and T. M. Chrisp, "The complex impedance response of fly-ash cements revisited," Cement and Concrete Research, vol. 34, no. 10, pp. 1837-1843, 2004.

[10] C. Shi, J. A. Stegemann, and R. J. Caldwell, "Effect of supplementary cementing materials on the specific conductivity of pore solution and its implications on the rapid chloride permeability test (AASHTO T277 and ASTM C1202) results," ACI Materials Journal, vol. 95, no. 4, pp. 389-394, 1998.

[11] W. J. McCarter, G. Starrs, and T. M. Chrisp, "Electrical conductivity, diffusion, and permeability of Portland cement-based mortars," Cement and Concrete Research, vol. 30, no. 9, pp. 1395$1400,2000$.

[12] E. J. Garboczi, L. M. Schwartz, and D. P. Bentz, "Modelling the D.C. electrical conductivity of mortar," Materials Research Society Symposia Proceedings, vol. 370, pp. 429-436, 1995.

[13] U. B. Halabe, Condition assessment of reinforced concrete structures using electromagnetic waves [Ph.D. thesis], Department of Civil \& Environmental Engineering, MIT, Cambridge, Mass, USA, 1990.

[14] S. Feng and P. N. Sen, "Geometrical model of conductive and dielectric properties of partially saturated rocks," Journal of Applied Physics, vol. 58, no. 8, pp. 3236-3243, 1985.

[15] W. M. K. Roddis, Concrete bridge deck assessment using thermography and radar [M.S. thesis], Department of Civil Engineering, Massachusetts Institute of Technology, Cambridge, Mass, USA, 1987.

[16] T. M. Chrisp, W. J. McCarter, G. Starrs, P. A. M. Basheer, and J. Blewett, "Depth-related variation in conductivity to study cover-zone concrete during wetting and drying," Cement and Concrete Composites, vol. 24, no. 5, pp. 415-426, 2002.

[17] H. C. Rhim, "Condition monitoring of deteriorating concrete dams using radar," Cement and Concrete Research, vol. 31, no. 3, pp. 363-373, 2001.

[18] S.-J. Kwon, M. Q. Feng, and S. S. Park, "Characterization of electromagnetic properties for durability performance and saturation in hardened cement mortar," NDT \& E International, vol. 43, no. 2, pp. 86-95, 2010.

[19] M. Q. Feng, F. De Flaviis, and Y. J. Kim, "Use of microwaves for damage detection of fiber reinforced polymer-wrapped concrete structures," Journal of Engineering Mechanics, vol. 128, no. 2, pp. 172-183, 2002.

[20] Y. J. Kim, L. Jofre, F. De Flaviis, and M. Q. Feng, "Microwave reflection tomography array for damage detection in concrete structures," in Proceedings of the IEEE MSS-S International Microwave Symposium Digest, vol. 51, pp. 651-654, June 2002.

[21] H. C. Rhim, Y. J. Kim, M. Q. Feng, S. K. Woo, and Y. C. Song, "Measurements of electromagnetic properties of concrete and fiber reinforced polymer for nondestructive testing," in Proceedings of the US-Korea Joint Seminar/Workshop on Smart Structures Technologies, Seoul, Republic of Korea, 2004.
[22] P. K. Metha and P. J. M. Monteiro, Concrete: Structure, Properties and Materials, Prentice Hall, Englewood Cliffs, NJ, USA, 2nd edition, 1993.

[23] A. M. Neville, Properties of Concrete, Longman, New York, NY, USA, 1996.

[24] H. W. Song, H. J. Cho, S. S. Park, K. J. Byun, and K. Maekawa, "Early-age cracking resistance evaluation of concrete structure," Concrete Science Engineering, vol. 3, pp. 62-72, 2001.

[25] T. Gonen and S. Yazicioglu, "The influence of compaction pores on sorptivity and carbonation of concrete," Construction and Building Materials, vol. 21, no. 5, pp. 1040-1045, 2007.

[26] H.-W. Song, S.-J. Kwon, K.-J. Byun, and C.-K. Park, "Predicting carbonation in early-aged cracked concrete," Cement and Concrete Research, vol. 36, no. 5, pp. 979-989, 2006.

[27] H. W. Song, S. J. Kwon, K. J. Byun, and C. K. Park, "A study on analytical technique of chloride diffusion considering characteristics of mixture design for high performance concrete using mineral admixture," Journal of the Korean Society of Civil Engineers, vol. 25, no. 1, pp. 213-223, 2005.

[28] H.-W. Song and S.-J. Kwon, "Permeability characteristics of carbonated concrete considering capillary pore structure," Cement and Concrete Research, vol. 37, no. 6, pp. 909-915, 2007.

[29] A. Nyshadham, C. L. Sibbald, and S. S. Stuchly, "Permittivity measurements using open-ended sensors and reference liquid calibration-an uncertainty analysis," IEEE Transactions on Microwave Theory and Techniques, vol. 40, no. 2, pp. 305-314, 1992.

[30] Korea Standard, Method of Test for Compressive Strength of Concrete, KSF 2405, 2005.

[31] Korea Standard, Standard test method for accelerated carbonation of concrete: KSF2584, 2005.

[32] Korea Standard, "Method for measuring carbonation depth of concrete," KSF 2596, 2004.

[33] P. W. Brown, C. L. Harner, and E. J. Prosen, "The effect of inorganic salts on tricalcium silicate hydration," Cement and Concrete Research, vol. 16, no. 1, pp. 17-22, 1986.

[34] A. K. Suryavanshi, J. D. Scantlebury, and S. B. Lyon, "Pore size distribution of OPC \& SRPC mortars in presence of chlorides," Cement and Concrete Research, vol. 25, no. 5, pp. 980-988, 1995.

[35] T. Ishida and K. Maekawa, "Modeling of $\mathrm{PH}$ profile in pore water based on mass transport and chemical equilibrium theory," Concrete Library International JSCE Publication, vol. 37, pp. 131-146, 2001.

[36] I. Izumi, D. Kita, and H. Maeda, Carbonation, Kibodang Publication, 1986.

[37] V. G. Papadakis, C. G. Vayenas, and M. N. Fardis, "Fundamental modeling and experimental investigation of concrete carbonation," ACI Materials Journal, vol. 88, no. 4, pp. 363-373, 1991.

[38] K. Maekawa, R. Chaube, and T. Kishi, Modeling of Concrete Performance, E\&FN SPON, 1999. 

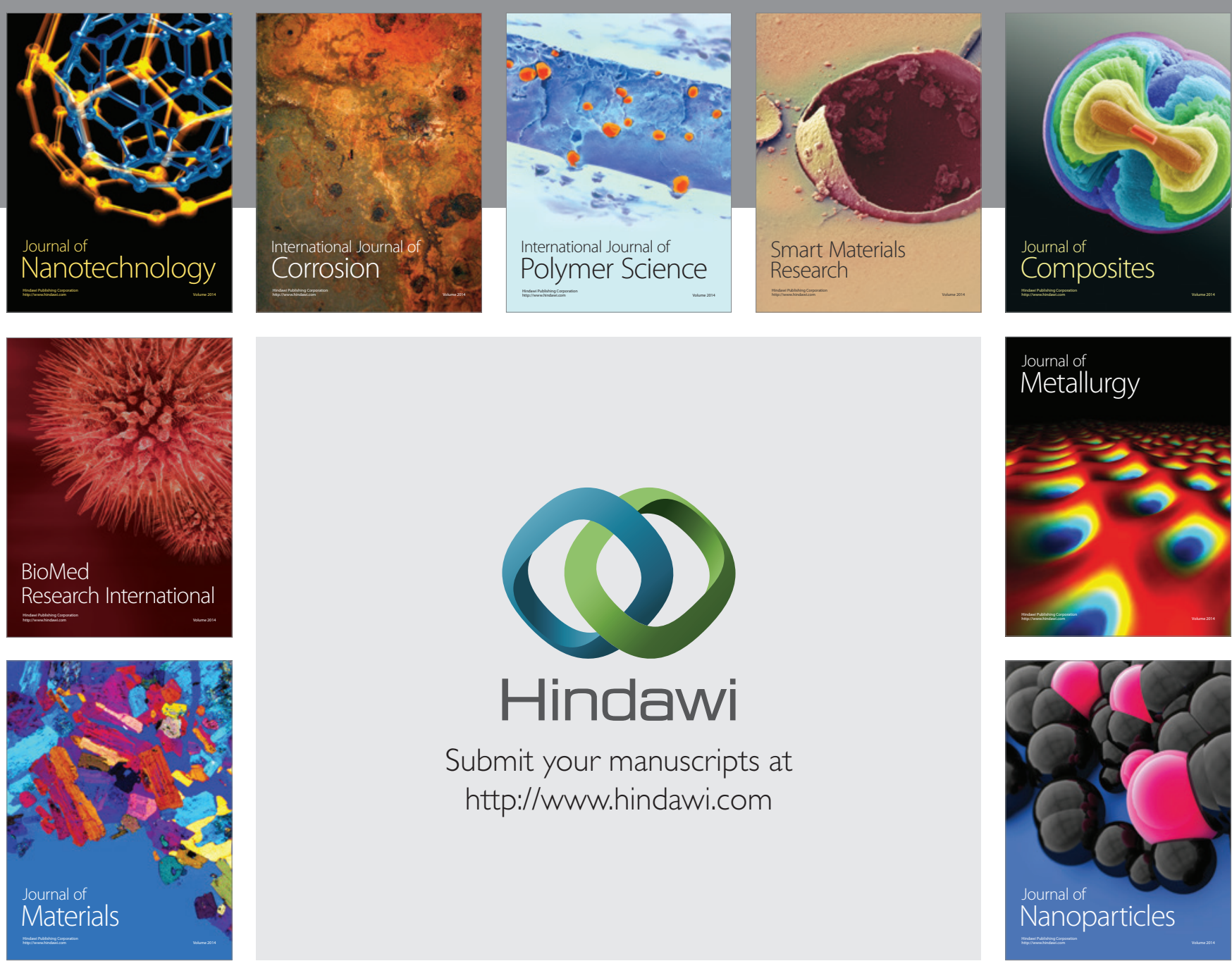

\section{Hindawi}

Submit your manuscripts at

http://www.hindawi.com

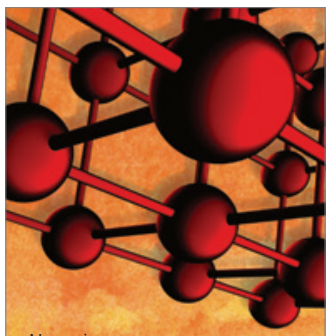

Materials Science and Engineering
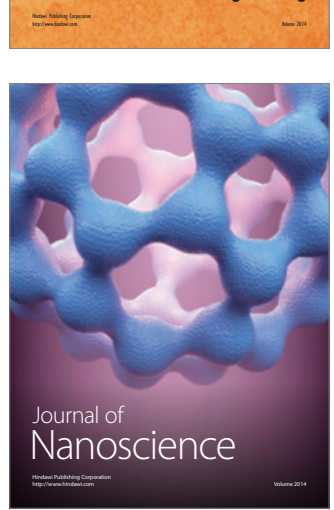
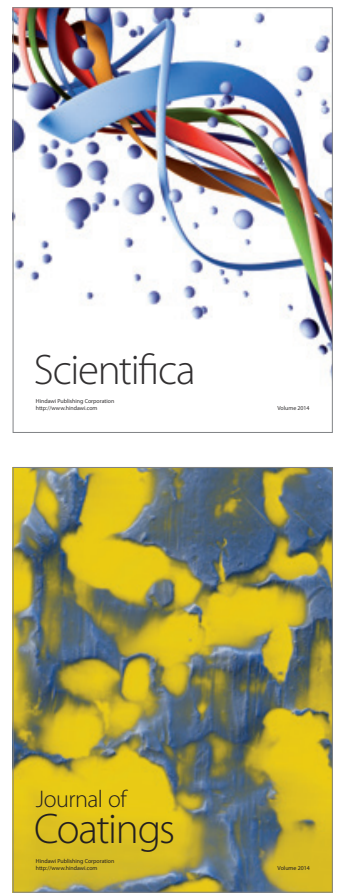
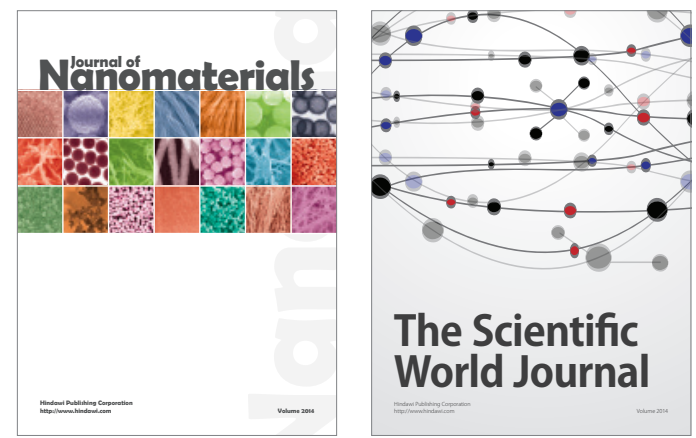

The Scientific World Journal
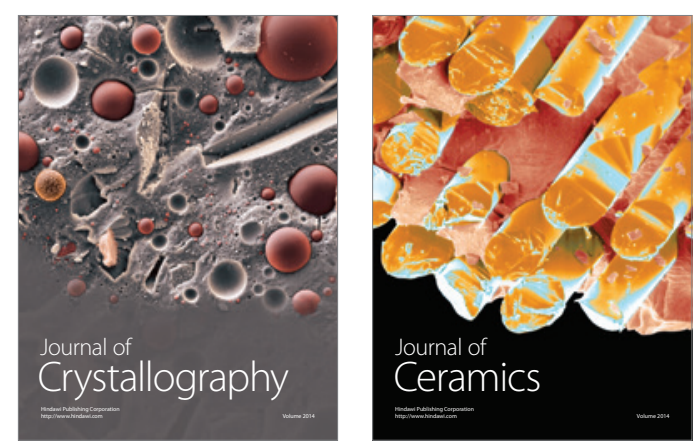
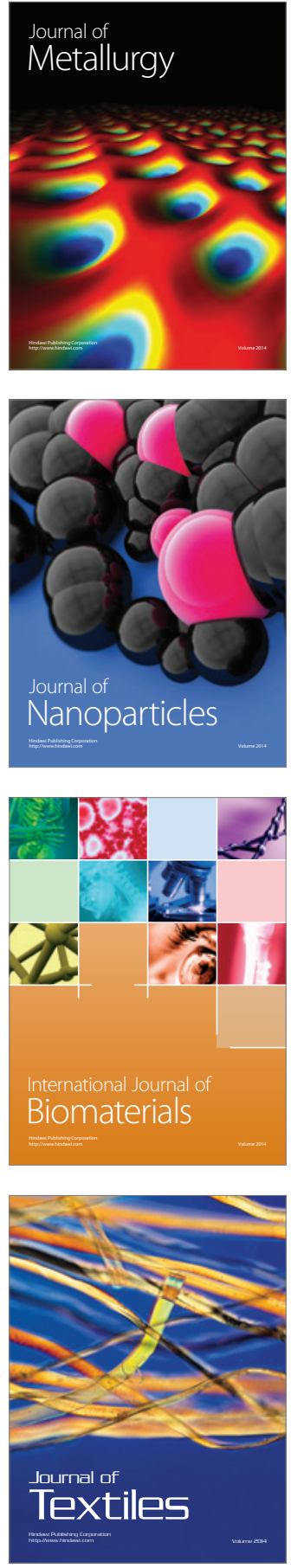